RESEARCH ARTICLE

\title{
Evaluation of genetic variation among populations of Dipcadi filamentosum Medik in some geographical regions in Nigeria based on RAPD markers
}

\author{
K.A. Abdulkareem ${ }^{1, *}$, O.T. Mustapha ${ }^{1}$ and R. Krishnamurthy ${ }^{2}$ \\ ${ }^{1}$ Department of Plant Biology, Faculty of Life Sciences, University of Ilorin, P.O. Box 1515, Ilorin, Nigeria. \\ ${ }^{2}$ C.G. Bhakta Institute of Biotechnology, Uka Tarsadia University, Maliba Campus, Bardoli-Mahuva, Tarsadi Dist., \\ Surat, Gujarat, India.
}

Received:25/01/2018; Accepted:9/05/2018

\begin{abstract}
The genetic variations were studied in different populations of Dipcadifilamentosum Medik collected from various geographical locations in Nigeria using 12 random amplified polymorphic DNA (RAPD) markers. Genomic DNA extraction was carried out using DNeasy Plant Mini Kit (QIAGEN, USA) and amplification of fragments was performed by Polymerase Chain Reaction. Amplification by 9 primers resulted in the detection of 95 loci and this represented $100 \%$ polymorphism. The sizes of the bands ranged between 1500-50bp in OPAE-14 and OPAC11.The Principal Component Analysis (PCA) showed that the genetic variation observed were accounted for by the first three components $(81.14 \%)$. Biplot analysis indicated that the markers effectively separated the populations into groups based on genetic similarity. The cluster analysis classified the populations into two major clusters with nine groups. The Neighbour joining clustered populations from YOB (north east,), OYO (south west) and KBA (north central) as genetically related and close neighbours.
\end{abstract}

Keywords: genetic diversity, Dipcadi filamentosum, biplot, amplification, RAPD markers, geographical regions.

\section{INTRODUCTION}

Dipcadifilamentosum belongs to the Family Hyacinthaceae. The family is represented by 55 species (Mabberley, 1990) distributed in the Southern Mediterranean region in Africa, Arabia, Socotra, Madagascar and India. The greatest diversity was found in South Africa where13 species are present (Stedje and Nordal 1987). In India 9 species are recorded (Deb and Dasgupta, 1978). Two to four species have been recorded from Arabia Peninsula (Baker, 1976, Blatter, 1919). Three species are identified in Nigeria (Adelanwa, 2008). It is a perennial herb of bulbous geophytes having a scaposed inflorescence of raceme type. The family is mostly found in seasonal climates with a pronounced dry season and is rare in tropical lowlands and forested areas. In Nigeria, it is found growing in regions where shady trees are absent (Temikotan et al., 2013). It grows well in sandy - loam soil. It has one to many leaves. The leaves are long and narrow arising from the base. Flowers are bell-shaped or tubular (Manning et al., 2004). The plants are found in the wild and are rarely cultivated. It is also a potential source of unique alkaloids such as bufadienloides, homoisoflavonones and steroidal compounds that may have a range of medicinal properties (Pohl et al., 2000). The leaves of D. filamentosum have been reported to contain phytochemicals such as tannin, saponin and flavanoid (Abdulkareem et al., 2014). It is also used in horticulture as an ornamental plant. Information on the genetic diversity of this species is scanty in literature. Thus, this study was carried out to determine the genetic variations which exist within the populations of $D$. filamentosum.

\section{MATERIALS AND METHODS}

\section{Sampling method}

D. filamentosum collections were done using cluster sampling method. Each of the geographical location was taken as a cluster. In each cluster, random sampling of D. filamentosum populations was carried out to ensure fair representation of the population of the plant in those regions in Nigeria.

\section{Genomic DNA Extraction}

The fresh leaves of $D$. filamentosum from the 13 samples obtained from four (4) geographical locations in Nigeria were used for DNA extraction (Table 1). One gram of leaf tissue was frozen with liquid nitrogen and ground into fine powder. Total genomic DNA was isolated from individual populations using DNeasy Plant Mini Kit (QIAGEN, USA). The quantity and quality of the DNA were checked using the spectrophotometer and $0.8 \%$ agarose gel electrophoresis respectively. Absorbance ratio of the DNA material at a wavelength of $260 \mathrm{~nm}$ and $280 \mathrm{~nm}$ was recorded to ascertain the quality of the genomic DNA. The DNA samples were stored at a temperature of $-4^{0} \mathrm{C}$ for RAPD analysis.

\section{PCR Amplification}

RAPD amplification was performed as described by (Priyanka and Gohar, 2012) using 12 decamer random primers (Xcelris, India). The amplification reactions were performed in a final volume of $25 \mu 1$ in $1 \times$ TAE buffer 
Table 1: Population of Dipcadi filamentosum collected from various sites in Nigeria.

\begin{tabular}{lllllll}
\hline $\begin{array}{c}\text { Geographical } \\
\text { location }\end{array}$ & Place of collection & $\begin{array}{c}\text { State of } \\
\text { collection }\end{array}$ & $\begin{array}{c}\text { Code } \\
\text { for each } \\
\text { location }\end{array}$ & $\begin{array}{c}* \text { Annual } \\
\text { rainfall (mm) }\end{array}$ & $\begin{array}{c}* \text { Mean } \\
\text { temp }\left({ }^{\circ} \mathbf{C}\right)\end{array}$ & Soil type \\
\hline South Western & Ado Ekiti & Ekiti & EKT & $1,605.40$ & 26.87 & Sandy loam \\
\cline { 2 - 7 } & Ogun & Ogun & OGN & $1,126.05$ & 25.05 & Sandy loam \\
\cline { 2 - 7 } & Oyo & Oyo & OYO & $1,318.10$ & 26.61 & Loamy \\
\hline North East & Maiduguri & Borno & MAI & 745.70 & 28.86 & Sand \\
\cline { 2 - 7 } & Damaturu & Yobe & YOB & 696.60 & 29.70 & Sand \\
\hline North Central & Sobi & Kwara & SOB & $1,046.30$ & 26.35 & Sandy \\
\cline { 2 - 7 } & Tanke & Kwara & TNK & $1,046.30$ & 26.35 & Sharp sands \\
\cline { 2 - 7 } & Unilorin & Kwara & UNI & $1,046.30$ & 26.35 & Sandy loam \\
\cline { 2 - 7 } & Kaiama (big) & Kwara & KAB & $1,046.30$ & 26.35 & Loamy \\
\hline Kaiama (medium) & Kwara & KAM & $1,046.30$ & 26.35 & Clay loamy \\
\hline Kaiama (small) & Kwara & KAS & $1,046.30$ & 26.35 & Loamy \\
\hline North West & Kabba & Kogi & KBA & NA & NA & Loamy clay \\
\hline
\end{tabular}

Table 2: The names of RAPD primers and their anneling temperatures.

\begin{tabular}{llll}
\hline S/no & Oligo name & Sequence 5'to 3', & $\left.\begin{array}{c}\text { Annealing } \\
\text { temperature }\end{array} \mathbf{(}^{\mathbf{C}} \mathbf{C}\right)$ \\
\hline $\mathbf{1}$ & OPD-17 & 5'TTTCCCACCG & 32 \\
$\mathbf{2}$ & OPAD -05 & 5'ACCGCATGGG & 34 \\
$\mathbf{3}$ & OPAE-11 & 5'AAGACCGGGA & 32 \\
$\mathbf{4}$ & OPAE-14 & 5'GAGAGGCTCC & 34 \\
$\mathbf{5}$ & OPAC-11 & 5'CCTGGGTCAG & 34 \\
$\mathbf{6}$ & OPAE-09 & 5'TGCCACGAGG & 34 \\
$\mathbf{7}$ & OPA-01 & 5'CAGGCCCTC & 34 \\
$\mathbf{8}$ & OPA-04 & 5'TGCCGAGCTG & 34 \\
$\mathbf{9}$ & OPA-05 & 5'AGGGGTCTTG & 32 \\
$\mathbf{1 0}$ & OPA-06 & 5'GGTCCCTGAC & 34 \\
$\mathbf{1 1}$ & OPA-07 & 5'GTGACGTAGG & 32 \\
$\mathbf{1 2}$ & OPA-09 & 5'GGGTAACGCC & 34 \\
\hline
\end{tabular}

containing 10mMTris- $\mathrm{HCl}(\mathrm{pH} 8.3), 400 \mu \mathrm{M}$ each of dNTPs $3 \mathrm{Mm} \mathrm{MgCl}_{2}, 0.4 \mu \mathrm{M}$ primers, 50ng template, 1 unit Taq DNA polymerase (Premix Taq Version 2.0, Cat. No.:XG334A, Xcelris, India). ( $1 \mu 1$ primer, $2 \mu 1$ template, $12.5 \mu \mathrm{l}$ of Master Mix and $9.5 \mu \mathrm{l}$ of Nuclease Free water). The reactions were carried out on a Gradient Master Thermo cycler (Eppendorff, Hamburg, Germany), with an initial denaturation temperature of $94^{\circ} \mathrm{C}$ for $5 \mathrm{~min}$ in 1 cycle followed by 35 amplification cycles consisting of three steps: $94^{\circ} \mathrm{C}$ for $1 \mathrm{~min}$, followed by the primers annealing temperatures from $32^{\circ} \mathrm{C}-34^{\circ} \mathrm{C}$ (Table 2) for $30 \mathrm{~s}$ and $72^{\circ} \mathrm{C}$ for $2 \mathrm{~min}$. After 35 cycles, the samples were subjected to a final extension steps for $10 \mathrm{~min}$ at $72^{\circ} \mathrm{C}$.

The PCR products were loaded on a $1.5 \%$ agarose gel in $1 \times$ TAE buffer. The PremixTaq Version 2.0 contained blue dye that allows monitoring of progress of migration during electrophoresis. Molecular marker of $100 \mathrm{bp}$ (Thermo Scientific, India) was used as standard to determine the fragment size of the amplification products on the gel. This was viewed in the UV light documentation unit (Gel Doc EZ Imager, BIO - RAD, USA). The analysis was performed thrice for each of the samples with each primer.

\section{DATA ANALYSIS}

The bands from the molecular studies were scored across the lanes. Their molecular weights were compared. The scoring of bands was carried out based on gel images. All the bands were treated as dominant markers and their homology were based on the level of migration on the gel. The bands were scored as present (1) or absent (0) across the genotypes and only reproducible bands in three amplification reactions were used in the final analysis. A data matrix was constructed. Principal Component and Coefficient of similarity tree were produced by clustering the similarity data using the statistical software package PAST (Paleontological Statistics). Cluster analysis was performed by agglomerative technique using the Unweighted Pair Group Method with arithmetic averages 
(UPGMA). Dendrogram were constructed using the UPGMA algorithms in the MEGA 4.0 software. The binary matrix was used to determine the genetic diversity and gene flow using the Popgene (10) version 1.3.2. (Nei, 1973; Saitou \& Nei, 1987) and Shannon's index (1) were estimated.

\section{RESULTS}

Out of the twelve primers used to analyse the 13 populations of Dipcadi filamentosum, a total of 9 primers produced 339 reproducible bands. A total of 95 loci were detected and this represented $100 \%$ polymorphism. Averages of seven to fifteen bands were produced by each primer. The banding patterns are shown in Figure 1. The sizes of the amplicon varied at all loci except in OPA - 06 and OPA - 09 (Table 3 ). The highest number of bands was produced in OPA-09 while the least were in OPA - 06 (Table 3). The principal component analyses for correlation of the performance of the various loci on the alleles revealed that the first three principal components accounted for approximately $81.14 \%$ of the total variation among the 13 populations (Table 4). The highest genetic variation observed was explained by component one $(43.082 \%)$, followed by the $22.380 \%$ in component two and the third component (15.680\%).The highest positive loading $(0.5903)$ of locus contributing to detection of genetic variations was in OPAD - 05 while least negative loading (0.08955) was in OPAE - 14 .

The biplot analysis of the markers on the populations revealed the spatial distribution of the populations in the four quadrants. The first quadrant consist of populations from MAI, UNI, SOB and OGN and the distribution of these four populations in quadrant -1 was marked by primers OPAE- 14 and they are close to the centroid. The second quadrant consists of four populations, KAM, KAB, EKT and KAS. Quadrant - III consists of three populations which were also close to the centroid and were delimited by markers OPAE-09, OPA-09, OPAC-11, OPA-6, OPA04 and OPAD-05. KAT in quadrant - IV was delimited by markers OPD-17 and OPA-01 (Figure 2).

Shannon's index (I) and Nei's genetic diversity (h) among the population from the different eco - geographical regions were estimated at $0.4378(\mathrm{SD}=0.0608)$ and $0.2021(0.0400)$ respectively. The mean coefficient of gene differentiation (GST) value was 0.0546. Estimate of gene flow $(\mathrm{Nm})$ in the population was 8.6510 .

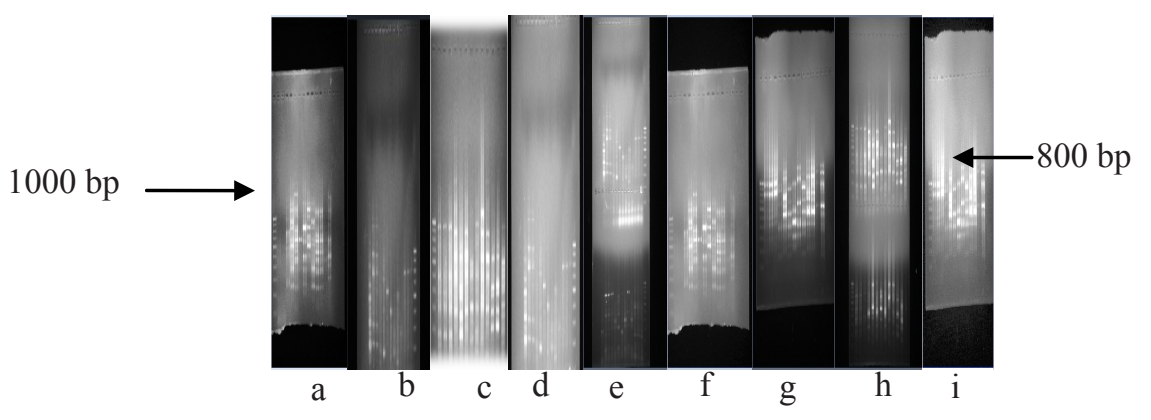

Figure 1: Band amplification of 9 RAPD markers: (a) OPAD - 05 (b) OPAC - 11(c) OPAE - 09 (d) OPA - 04 (e) OPA - 09 (f) OPD -17 (g) OPA - 01 (h) OPAE - 14 (i) OPA - 06 used for diversity study of 13 populations of D. filamentosum.

Table 3: Amplification parameters of RAPD marker in D. filamentosum.

\begin{tabular}{llccc}
\hline $\begin{array}{c}\text { Oligo } \\
\text { name }\end{array}$ & Sequence 5'to 3' & $\begin{array}{c}\text { Amplicon size } \\
(\mathbf{b p})\end{array}$ & $\begin{array}{c}\text { Total amplicons in } \\
\text { genotype }\end{array}$ & $\begin{array}{c}\text { Amplicons per } \\
\text { genotype }\end{array}$ \\
\hline OPD-17 & 5'TTTCCCACCGG & $1200-300$ & 41 & 11 \\
OPAD -05 & 5'ACCGCATGGG & $1000-100$ & 33 & 13 \\
OPAE-14 & 5'GAGAGGCTCC & $1500-100$ & 46 & 7 \\
OPAC-11 & 5'CCTGGGTCAG & $1300-50$ & 27 & 11 \\
OPAE-09 & 5'TGCCACGAGG & $1000-50$ & 35 & 10 \\
OPA-01 & 5'CAGGCCCTTC & $1000-200$ & 49 & 15 \\
OPA-04 & 5'TGCCGAGCTG & $1200-200$ & 35 & 9 \\
OPA-06 & 5'GGTCCCTGAC & $1000-300$ & 22 & 9 \\
OPA-09 & 5'GGGTAACGCC & $1000-300$ & 51 & 10 \\
\hline
\end{tabular}

Table 4: Principal Component Analysis (Correlation) using RAPD marker.

\begin{tabular}{ccc}
\hline Principal Component & Eigen Value & \% Variance \\
\hline $\mathbf{1}$ & 3.87741 & 43.082 \\
$\mathbf{2}$ & 2.01418 & 22.380 \\
$\mathbf{3}$ & 1.41116 & 15.680 \\
\hline
\end{tabular}




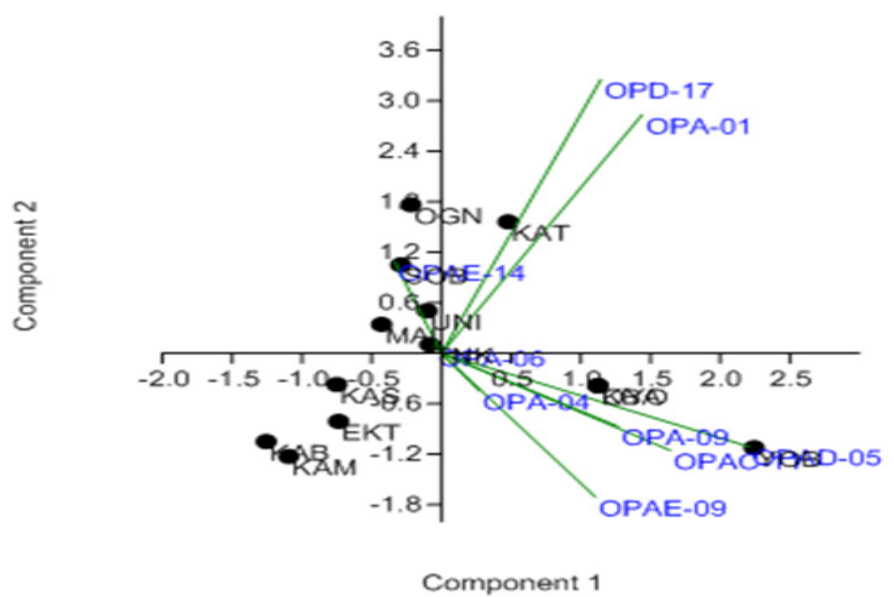

Figure 2: Biplot of Principal component analysis (PCA) of Dipcadi filamentosum using RAPD markers.

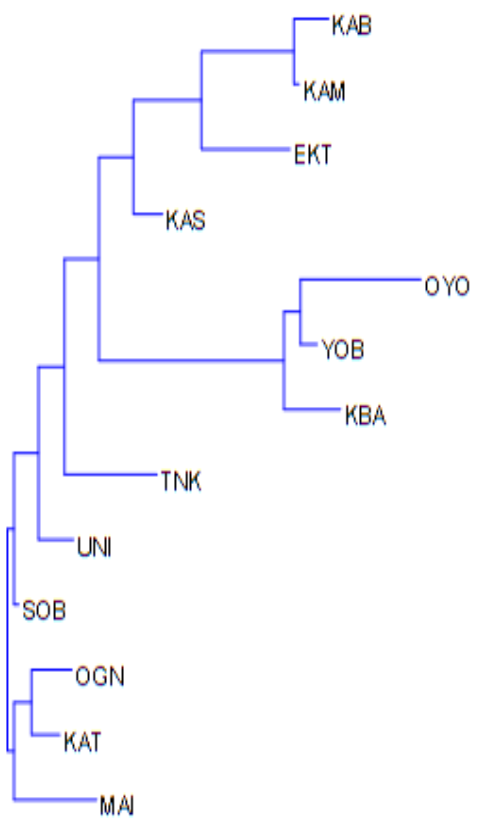

Figure 3: Neighbour joining clustering of 13 Dipcadi filamentosum populations using RAPD markers.

Neighbour joining diagram of the 13 D. filamentosum populations evaluated the genetic diversity is represented in Figure 3. The MAI populations from North East formed the base for all the populations. The analysis revealed the linkage between the North West populations (KAT) and the South West collections (OGN)as close neighbours. SOB, UNI and TNK are distantly related. OYO, YOB and KBA populations are close neighbours. KAM is a progenitor of KAB (Figure 3).

The cluster analysis separated the populations into two major clusters. Cluster I consists of seven groups with ten populations. Cluster II consists of two groups with three populations. The genetic distance values are between 0.14 and 0.64 . The KAB and KAM were clustered together at a genetic distance of 0.08 while KAS is joined as a separate node at a distance of 0.28 but as a distant relative arising from KAB and KAM respectively. OGN and KAT have a genetic distance value of 0.32 (Figure 4).

\section{DISCUSSION}

In genetic diversity identification, the use of molecular markers can provide new insights to better understanding of the genetic variation found in any germplasm collection. The use of morphological or phenotypic traits can be employed in the determination of genetic diversity but these traits are influenced by temperature, soil type and other environmental conditions which are often difficult to evaluate as noted by Ozrenk et al. (2009). The use of RAPD markers enabled the random section of DNA to be rapidly reproduced using short oligonucleotide primers. This has 


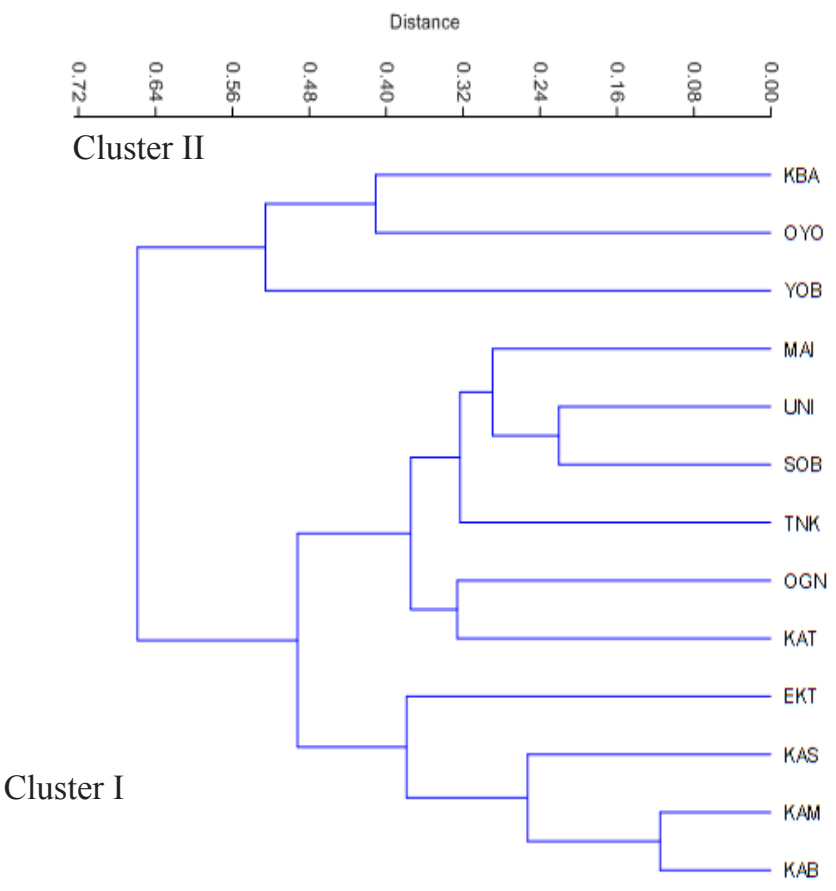

Figure 4: Cluster analysis (UPGMA) Dendrogram of 13 Dipcadi filamentosum populations using RAPD markers.

assisted in showing that genetic diversity exists among the populations of $D$. filamentosum.

Different primers used were able to show variation in their ability to detect polymorphism hence the $100 \%$ polymorphism generated by the RAPD markers in this study among the D. filamentosum populations. According to Ajibade et al. (2000) a high number of alleles and polymorphism are of great importance for the correct estimation of genetic diversity of any germplasm. The high polymorphic results in this work is in consonance with the work of Guasmi et al. (2012) where 100\% polymorphism was obtained in their use of RAPD markers to study the genetic diversity among South Tunisian barley. A total of 95 loci detected in this study showed that the markers are both effective and informative in the study of the molecular characterization of $D$. filamentosum. This is in consonant with the work of Singh et al. (2012) in their study of genetic diversity in Capsicum landraces.

The allelic richness was exhibited by the seven to fifteen bands produced by each primer. Powell et al. (1996) asserted that different markers might reveal different classes of variation. The clustering obtained was not according to the geographical origin. Populations such OGN, KAT and MAI that are from different geographical regions are clustered together. The NJ showed that OGN has sequenced more amino acid than KAT due to the fact that it has accumulated mutations at a higher rate as indicated by the length of the branch joining them. RAPD studies are mostly used at taxonomic ranks where DNA sequences or RFLPs have failed to detect differences between accessions or taxa (Bachmann and Hombergen, 1996; Bachmann 1997; Wolfe and Liston, 1998).

MAI has mutated more than OGN and KAT. OYO and YOB were clustered together as closely related with OYO; however the length of the branch showed accumulated mutation in their genome. According to molecular analysis, the geographical origin of specimens has no influence on the cluster obtained. Potolina et al. (1999) in their study of the phylogeny of Vicia reported that RAPD is more informative in inferring relationships among closely related taxa as a greater number of polymorphic sites throughout the whole genome could be analysed.

RAPD analysis proved useful in finding the genetic differences among phenotypically indiscriminate variants of $D$. filamentosum. RAPD markers are proven to be useful in self-pollinating species with a low level of intraspecific polymorphism (Meunier and Grimont, 1993). This work has shown that even where a high level of intraspecific polymorphism is obtained, RAPD are also useful as demonstrated by the 95 polymorphic loci detected in this work. The study on the genetic diversity of $D$. filamentosum using RAPD molecular markers produced 339 reproducible bands. Earlier works have shown that RAPD markers reveals even small genetic differences as a large part of the nuclear genome are scanned (Rieseberg et al., 1993; Staub et al., 1997).

The distributions of the populations as shown in the study were in different clusters and co-ordinates according to the biplot analysis. This is an indication of the action of the markers on the genotypes in separating the populations into quadrants. The spatial closeness of the populations showed their genetic similarity. Those far from the centroid are said to be genetically diverse and distantly related. Those that have similar genetic background and are closely related as delimited by the markers are close to or on the centroid. The dispersion of the markers from the centroid points to their effectiveness in delimiting the populations. This is similar to the results of Maniruzzaman et al., (2010) in their study of Allium cepa using RAPD markers. 


\section{CONCLUSION}

The presence of genetic variation in the populations of Dipcadi filamentosum by the use of RAPD markers has been established with the high percentage of polymorphism obtained. This will assist in the determination of the genetic relationship through the knowledge of their evolutionary background by providing a chance to compare them at molecular level.

\section{REFERENCES}

Abdulkareem, K.A., Garuba, T., Abdulrasaq, R. and Mustapha, O.T. (2014). Studies on the Morphology and Phytochemical Constituents of Dipcadi filamentosum in Two States of North-Central Nigeria. Journal of Chemical, Biological and Physical Science. 4(3): 2158-2164.

Adelanwa, M.A. (2008). Cyto-morphological studies of the family Leguminosae (Fabaceae) from Northern Nigeria. Unpublished Ph.D. Thesis, University of Jos, Jos, Nigeria. 300pp.

Ajibade,S.R., Weeden,N.F. and Michite, S. (2000). Inter Simple Sequence Repeat analysis of genetic relationships in the genus Vigna. Eupytical, 111:47-55.

Bachmann, K. (1997). Nuclear DNA markers in Plant Biosystematics Research. Opera Botanica 132:137-148.

Bachmann, K. and Hombergen, E.J. (1996). Mapping genes for phenotypic variation in Microseris (Lacttuceae) with molecular markers. In Compositae: Biology and Utilization, Vol. 2 (Caligari, P. D.S. and Hind, D. J. N., eds.), Kew Gardens, London, Pp. 23-43.

Baker, (1976). Hyacinthaceae Dipcadi palustre Baker bull. Herb.Boissier Ser.ll.iv 1000.

Blatter, W. (1919). Hyacinthaceae Dipcadi polyphyllum Baker. Bull. Herb Boissier ser. 11 iv.1001. (IK).

Deb, D.B. and Dasgupta, S. (1978). A new species of Dipcadi Medik(Liliaceae). Indian Forester 104 (11): 754-756.

Guasmi, F., Elfallah, W., Hannachi, H., Feres, K. and Touil, L. (2012). The use of ISSR and RAPD markers for genetic Diversity among South Tunisian Barley. International Scholarly Research Notices 10:1-10.

Mabberley, D.J. (1990). The plant book. Cambridge University Press, Cambridge.

Maniruzzaman, M.E., Haque, M.E., Haque, M.M., Sayem,M.A. and Al-Amin, M. (2010). Molecular characterization of onion (Allium cepa) using RAPD markers. Bangladesh Journal of Agricultural Resources35(2):313-322.

Manning, J.C., Goldblatt, P. and Fay, M.F. (2004). A revised generic synopsis of Hyacinthaceae in SubSaharan Africa, based on molecular evidence, including new combinations and the new tribe Pseudoprospereae. Edinburg Journal of Botany 60:533-568.

Meunier, J. R. and Grimont, P.A.D. (1993). Factors affecting reproducibility of Random Amplified Polymorphic DNA fingerprinting. Molecular Cell Probes 7: 293-858.

Nei, M. (1973). Analysis of gene diversity in subdivided populations. Proceedings of National Academy of Sciences United States of America 70: 3321-3323.
Ozrenk, K., Gazioglu, S. R. I., Erdinc, C., Guleryuz, M. and Aykanat, A. (2009). Molecular characterization of mulberry germplasm from Eastern Anatolia. African Journal of Biotechnology 9(1): 1-6.

Pohl, T. S., Crouch, N. R. and Mulholland, D.A. (2000). Southern African Hyacinthaceae: Chemistry, bioactivity and ethnobotany. Curriculum of Organic Chemistry 4:1287- 1324.

Potolina, E., Tomooka, N., Vaughan, D.A., Alexandrova, T., XU, R. (1999). Phylogeny of Vicia subgenus Vicia (Fabaceae) based on the analysis of RAPDs and RFLP of PCR-amplified chloroplast genes. Genetic Resources and Crop Evolution 46:149-161.

Powell, W., Morgante, M., Andre, C., Hanafey, M., Vogel, J., Tingey, S. and Rafalski, A. (1996). The comparison of RFLP, RAPD, AFLP and SSR (microsatellite) markers for germplasm analysis. Molecular Breeding 2: 225-238.

Priyanka , G. and Gohar, T. (2012). Molecular Characterization of six populations of Acorus calamus L. using random amplified polymorphic DNA (RAPD) markers. AfricanJournal of Biotechnology 11 (40): 9522- 9526.

Rieseberg, L. H., Choi, H., Chan, R. and Spore, C. (1993). Genomic map of a diploid hybrid species. Heredity $\mathbf{7 0}$ : 285-293.

Saitou, N., and Nei, M. (1987). The neighbour- joining method: a new method for reconstructing phylogenetic trees. Molecular Biology and Evolution 4: 406-425.

Singh S., Singh, D.R., Balaji, R., Nayak, D., Singh, A.K. and Kumar, N. (2012). Molecular and Functional diversity of Capsicum land racesof Andaman Islands. Academic Journals 12(39): 5729-5737.

Staub, J. E., Serquen, F.C. and Bacher, J. (1997). Mapping and ATL analysis of horticultural traits in a narrow cross in Cucumber (Cucumis sativus L.) using RandomAmplified Polymorphic DNA markers. Molecular breeding 3:257-268.

Stedje, B. and Nordal, I. (1987). Cytogeographical studies of Hyacinthaceae in African South of the Sagra desert. Nordic Journal of Botany 7(1):53-65.

Temikotan, T., Akinyele, B.O., Odiyi, A.C., Arotupin, O.J. (2013). Phytochemicals of some membersof the Family Hyacinthaceae and their significance in plant protection. Proceedings of the world congress on Engineering London, U.K. 2: 978-988.

Wolfe, A. D. and Liston, A. (1998). Contribution of PCRbased methods to plant systematic and evolutionary biology: In Soltis, D. E., Soltis P.S. and Doyle, J.J. (Eds.) Molecular Systematics of Plants II: DNA Sequencing, Dordrecht, Kiuwer, Pp 43-86. 